\title{
INFLEXIONES DE LA VIDA: UN PAR DE LECCIONES
}

\author{
VERONICA GRUNEWALD CONDORI \\ Universidad de Concepción (Chile)
}

Recibido: 14/05/2009

Aceptado: 28/05/2009

\section{Introducción}

La silla tonta atrapa mi cuerpo Como un imán, no me puedo levantar Desapareces a gotas de recónditas regiones, neuronas en la nigra reclaman tu corporeidad

¿Porqué abandonas tu nido?

Qué te hizo elevar alas?

No te dejes abatir regresa del exilio,

manos temblorosas te reclaman

¡Asciende!

Enciende el movimiento

Da vida a los giros

Levanta la marcha

¡Sálvame de tropiezos!

Selgina, Sifrol, Prolopa

Es la danza de la dopamina

Pequeñas dosis de divinidad ${ }^{1}$

Existen puntos de inflexión en la vida que la hacen parecer una pista de carreras con obstáculos que hay que sortear con la vista vendada. Tenemos sólo esta oportunidad de vida, la que según Sartre es la «... única vida de la que sé y por la que me esfuerzo momento a momento» ${ }^{2}$, siendo esta vida el escenario de la batalla entre el deseo y el amor por vivir, ella quiere que luchemos por ella. «Querer vivir y saber que no podemos querer vivir para siempre no significa querer por fin, morir» ${ }^{3}$. La reflexión es posible desde la

1. Poema de la autora.

2. SARTRE, J.P. Kierkegaard vivo: Una reconsideración. Madrid, Encuentro, 2005, p.116.

3. Ibíd.

Feminismo/s 13, junio 2009, pp. 21-32 
distancia con el adversario, encontrar el objeto de la batalla. ¿Qué es lo que quiero ahora? Ya que no quiero la muerte.

De este modo, no sería posible memorizar el camino hacia la muerte. Volver a caminar por la vida conlleva otro nacimiento y otra muerte, significando a su vez, otra vida, que no sería la mía, a la cual no le serviría mi equipaje de viaje, o dicho de otro modo, todas aquellas experiencias evolutivas o puntos de inflexión que acumulé en el camino. Sólo coincidimos en los puntos de partida y de llegada pues la certeza del nacimiento y la constante lucha por la vida o contra la muerte se transforma en un desafío que instintivamente asumimos por el deseo de vivir, o más bien, por el deseo de la vida de mantenernos a su lado. Sartre dice «... cuando la consideración es capaz de detenerse lo bastante en el pensamiento de la vida, descubre que más bien es ésta la que se nos aferra a nosotros» ${ }^{4}$. La vida perdura entre los puntos de inflexión inicial y final, no hay líneas rectas, no hay perfección en su trazado, sin embargo, con la imperfección de la no linealidad, con los inesperados puntos de inflexión, parece ser una perfecta sinfonía en el espacio que nos ha elegido para experimentar el viaje o tal vez, para alimentar la energía que necesita para su movimiento.

El nacimiento es un punto de partida del tiempo individual, el Cronos, «que para los griegos era la deidad representativa de tiempo, la linealidad entre la vida y la muerte», significa a la vez un kairós para los espectadores de nuestro nacimiento o retorno a la vida. Valencia ${ }^{5}$ señala que Kairós representa el momento de la felicidad, la oportunidad, del cambio y la innovación activa, el momento decisivo, indica que vivir esta experiencia supone la capacidad individual de distender el tiempo conscientemente para oponer su avance. Agrego que representa el cambio de rumbo, la esquina, el vértice, la profundidad del pozo o la cumbre. No es posible ascender más, por lo que comienza el descenso o no es posible caer más en consecuencia, el ascenso es inminente y todo sucede en un tiempo y espacio determinado, marcando vida y muerte en el devenir de la eternidad.

Estos puntos de inflexión son la oportunidad para que el sujeto autoconscientemente asuma la muerte, y adquiera para sí «uno de los incentivos más fuertes de la vida», como plantea Fromm ${ }^{6}$ sobre la época actual, en que la negación de la muerte reprime la posibilidad de los individuos de experimentar

4. Ibíd.

5. VAlenciA, G. Entre Cronos y Kairós, las formas del tiempo sociohistórico. Barcelona, Antrophos, 2007.

6. Fromm, E. El Miedo a la Libertad. Barcelona, Paidós, 2006, p. 277. 
intensa y profundamente la felicidad y el entusiasmo. Esto, por fortuna, «no quiere decir que no existan los elementos reprimidos» ${ }^{7}$. Asumiendo la muerte, asumimos también la fragilidad como característica humana, y concientes de lo inminente, somos capaces de vestir la capa de la libertad, transformando el punto de inflexión, el instante preciso, que se presenta distendido a la espera de nuestras virtudes o capacidades, en una puerta que se abre en el vacío hacia otro camino y sólo por ese instante tenemos la oportunidad de decidir hacia donde irá la vida, hacia dónde se desplazará la curva vital cuyo momento desató tanta energía que desplaza las expectativas, las proyecciones y hasta los sueños. Capacidades internas que tienen que ver con la libertad para tomar una decisión desde el yo individual, ahora libre del miedo a la muerte, como parte del humano ejercicio de la voluntad propia.

En la mitad del curso de la vida, hemos aprendido a aceptar la trayectoria indiscutida hacia la muerte, ganando tiempo a la vez para replantear las estrategias, revalorando las motivaciones que nos impulsan a seguir en la batalla. ¿Hacia dónde estoy llevando mi vida? ¿Qué estoy aportando? ¿Cuál está siendo mi legado? ¿Cumplí las expectativas familiares? Un sinnúmero de cuestionamientos vitales, de cuya respuesta depende la fuerza con que retome la batalla o el abandono de las armas, la renuncia, la entrega que lleve rápidamente la vida al final del camino.

\section{Los Mensajeros}

«Señora, usted tiene la enfermedad de parkinson» ${ }^{8}$. Las estadísticas de la enfermedad la sitúan principalmente en personas sobre los 65 años, entonces, ¿quién espera una enfermedad neurodegenerativa, de nombre extraño, si no ha cumplido aún los 40 años? ¿Quién quiere ser la excepción? Acompañada de la huella genética o «el legado europeo» como dijo mi neurólogo y la oxidación celular, las neuronas no supieron de tiempo, degenerando y muriendo, dejándome atrapada en la fragilidad de la enfermedad.

7. Ibíd.

8. Enfermedad neurodegenerativa, descrita por el doctor James Parkinson en 1817, y que se puede desarrollar principalmente en las personas mayores de 60 años. Afecta a las células dopaminérgicas, encargadas de producir dopamina y que controlan los movimientos musculares. Debido a esta alteración, de muerte de las células o mal funcionamiento, los movimientos musculares se alteran ocasionando bradiquinesia, temblores, problemas de equilibrio, alteración del sueño, alteración en la voz, etc. No existe cura conocida y los medicamentos tienen como objetivo controlar los síntomas ocasionando en algunos casos efectos secundarios. (<http://www.neurocirugia.com/static.php?page=parkinson>, consultado el 8/05/2009). 
Entre TAC y otros exámenes, y pasando de un médico a otro, transcurrieron los primeros meses, aprendiendo sobre enfermedades neurológicas, leyendo entre líneas para tratar de descubrir que había un error en el diagnóstico, que no terminaría en el estadio 5 de Hoehn y $\mathrm{Yahr}^{9}$, usando pañales y dependiendo de otros para cosas tan básicas como peinarme. Acostumbrada a dar órdenes y ejerciendo funciones de control, de pronto no podía controlar mis propios movimientos. Pero en su trance, la sibila ya había desvelado los símbolos del oráculo con palabras que no tenían otra interpretación y ningún sacrificio u ofrenda cambiarían esa lectura.

Habiendo enfrentado antes otros puntos de inflexión; la ausencia de un padre, el abandono temprano de mi madre o la maternidad en la adolescencia, encuentro las armas para identificar esta otra puerta, otra oportunidad y fuerzo el avance del tiempo buscando en el espacio que debo llenar, la respuesta correcta, la acción vital que me lleve a la vida otra vez. Descubro entonces que para salvarme del dominio de la enfermedad debo movilizar aquella parte de mi cuerpo que paradójicamente no ha sido atrapada, digo paradójicamente, pues allí, donde radica su origen, justo donde la falta de dopamina ha encarcelado gran parte de mi cuerpo y algunas funciones básicas, es también donde encuentro las fuerzas, la base para la reunificación de mi espíritu con este cuerpo enfermo. El cerebro lo contiene todo.

Cambio de itinerario, dice el secuestrador de mi cuerpo femenino. ¿Hacia dónde iba este vuelo? Múltiples destinos hubiera sido la respuesta, un planificado, complejo y restringido itinerario. Un pasaje comprado por anticipado a ninguna parte, ya que el mañana es el vacío, el futuro es el tiempo que no ha llegado, no existe. Yo, en cambio, tengo movimiento, a veces no es físicamente evidente, pero se mueve, late mi corazón, los pensamientos emergen uno tras otro, las ideas, los recuerdos, los colores y sentimientos. En este ejercicio de voluntad, el yo interno se hace libre para iniciar el viaje «a la expansión genuina del yo», el que, según Fromm ${ }^{10}$, se despliega desde el núcleo particular y único que identifica a cada persona.

\section{La mujer}

Así fueron quedando atrás las sutilezas, y el cofre de cosméticos fue reemplazado por uno de medicamentos. La necesidad de prevenir caídas y tropiezos

9. Escala neurológica de Hoehn y Yahr de 5 estadios de la enfermedad de Parkinson que ubica los períodos de avance de la enfermedad desde sus inicios (Estadio 1) con los primeros síntomas hasta la inmovilidad total (Estadio 5). (<http://www.uninet.edu/ neurocon/neurologia/escalas/parkinson.html\#HY>, consultado el 8/05/2009)

10. Fromm, E. Anatomía de la destructividad humana. Méjico, Siglo XXI, 1986, p. 301. 
me llevó a despedir mis tacones más altos para tomar otros más cómodos, y ropa holgada, fácil de poner. Dejé de ocuparme de depilar mis cejas, desde que mis manos no coordinaban movimientos, dejé de mirar las vitrinas porque iquién quiere zapatos bellos y ropa bonita si camina como si tuviera 90 años? Mientras caminaba arrastrando los pies, los intereses cambiaron y los sueños quedaron reducidos a vivir un buen día. Un día sin caídas, un día en que al menos pudiera asearme sola.

En este kairós establezco la oportunidad, abro la puerta hacia algo nuevo, $\tan$ distinto que transformaré personalmente en motivo de alegría. En el tiempo anterior no pensaba en esto, todo era trabajo y las satisfacciones provenían de un aumento de sueldo, un ascenso, éxito laboral, competencia o las felicitaciones de la jefa. Pero la vida no es sólo trabajo como tampoco lo es la enfermedad.

Asumida en el desafío de vivir el punto de inflexión que se presenta, sin importar la estética, porque no necesito escotes ni ropa ceñida para estar cómoda conmigo misma, yo cómplice, yo compañera reunidas conmigo, dentro de mí y son la fortaleza que me da el saber que mantengo la unidad y no me gana el conformismo ${ }^{11}$, con ello aseguro gran parte de mi salud psíquica y mi individualidad. La certeza de ser auténtica, espontánea, natural y transparente sincronizando con verdad el desafío cotidiano y las sutilezas del espacio interior son el mejor medicamento. Rompiendo esquemas, desafiando las definiciones, las actitudes esperadas por la sociedad, es la manera de no perder la individualidad, y con ello, no dejar al intruso fantasma arrollar junto con mi cuerpo, mi mente.

Cambio de apariencia, cuando hablar de apariencia en una sociedad como la nuestra, en que la mujer es mayormente valorada por su aspecto exterior, implica un desafío adicional que finalmente elegí no asumir. La imagen social de la mujer en este país es la de un ser humano superior, se espera de ella el orden doméstico, la educación de los hijos, la belleza o estética aplicada. Por mi parte, asumo el ideario de la mujer aymara que difiere diametralmente de la concepción occidental de la mujer que la reduce a cuerpo bello, carente de capacidad de decisión y sin acceso a todas las esferas de poder. En un mundo occidental con sus historias y leyes escritas por hombres que postergaron el desarrollo del par mujer remitiéndola a las tareas no productivas desde el punto de vista económico, y reafirmando su inferioridad desde la perspectiva de la producción, condicionando su participación activa. Pese a la existencia de valiosas excepciones a lo largo de la historia, la arraigada amenaza de ser

11. Fromm, E. Anatomía de la destructividad humana. Op. cit., p. 286.

Feminismo/s 13, junio 2009, pp. 21-32 
acusada de bruja durante la Edad Media, reprimió cualquier intento de una mujer de demostrar inteligencia o conocimiento mayor que los de un hombre común. La mujer carecía de derechos civiles, y con los amplios poderes de la Iglesia, incluso a esposos y hermanos les era permitido denunciar a sus hermanas o esposas, entregarlas a la santa Iglesia para proteger a las sociedades de la malignidad y repartirse sus bienes después de la tortura y muerte de la amenazante bruja. Las principales acusadas eran aquellas que habían alcanzado en sus comunidades una posición de respeto y aprecio por sus conocimientos de herbolarias ${ }^{12}$.

Desde el mujerío indígena me desplazo entre la naturaleza como parte de ella, conformando junto con el hombre la indisoluble complementariedad, somos uno con la tierra, el agua, el viento, la lluvia y el fuego. Constituye la mujer aymara, en cuanto complemento y dualidad, parte de la naturaleza, de la pachamama, ni mejor ni peor, ni más ni menos, ni bruja ni santa. Mujer aymara, mujer y hombre, parte de los sagrados ciclos de la naturaleza.

Una enfermedad discapacitante es una falta a la normalidad, las mujeres madres, esposas, no podemos enfermar, no hay espacio para vivir en la enfermedad, para envolverse con ella y dejar que nutra el inmenso punto de inflexión, el martillazo, el golpe bajo. Esta enfermedad discapacitante es también lo inesperado para la familia, también significa para cada uno de ellos un cambio profundo. La mayoría de los hijos discapacitados tienen a sus madres y ¿a quién tienen ellas en la discapacidad? Es probable que esta pregunta no tenga respuesta. Tal vez se encuentre en el resumen de la vida, en ese instante en que los recuerdos llegan vívidos a la memoria junto con las personas halladas en el camino, y éstas sean a la vez el pequeño soporte, el bastón. De formas diversas, aunque no digan nada, incluso la compasión es un apoyo, pues permite la rebelión, permite que tenga fuerzas para evitar el ataque de la enfermedad al tesoro más guardado, mi yo interno, la que soy, parte de la naturaleza y la creación, allí no llega, no lo tiene permitido.

Suficiente ha logrado ganando espacio físico en mi cuerpo y no avanza, pues he creado una barrera que sostengo con esas pequeñas miradas diarias, sean éstas de solidaridad, de impotencia de los más cercanos, de incógnita que vienen de extraños. Con todo lo que encuentro en las energías externas, que absorbo y transformo, armo esta barrera, de pequeñas fortalezas.

12. Wolsfenberger, L. Cuerpo de Mujer, campo de batalla. Méjico, Plaza y Valdés, 2001, p. 226. 


\section{El silencio}

Durante varios meses, después del diagnóstico no se hablaba de la enfermedad. La evidente lentitud, los problemas de marcha y dificultades para comer, era como si no existiesen, nadie mencionaba la enfermedad. Quienes estaban a mi alrededor se estaban autoprotegiendo, aplicando el instinto de fuga, ante el miedo de ser afectados emocionalmente con la nueva condición que estaba presentando esta mujer que conocían desde la salud y el dinamismo. Estaba rompiendo los esquemas por ellos conocidos y, siguiendo a Fromm ${ }^{13}$, como el hombre necesita objetos de orientación, que se transforman en importantes pilares de su equilibrio emocional, el que se ve amenazado por el nuevo hecho: la enfermedad en la persona querida, respetada, conocida. Entonces, si bien hay dos caminos, sólo hay uno posible y es el camino de la huida. Asumen con la huida la defensa de su propio equilibrio, y la huida no es concreta, es sólo una fuga emocional, no están presentes cuando la amenaza aparece.

Con dificultades, poco a poco, el tema se fue incorporando al evento cotidiano, como es necesario el contenido, tenía que ser parte del diario vivir, si era parte de mí y esconderlo, hacer como que no existía, no era el camino. En casa, hoy se habla de ello, atendiendo en parte las noticias científicas, los reportajes, mencionando abiertamente la palabra «parkinson». Pero para los familiares que no viven bajo el mismo techo, es difícil todavía asumir mi presencia discapacitada. Les cuesta asumir que estoy enferma y que físicamente no es lo mismo que antes, pese a los esfuerzos. Otros familiares me abrazan emocionados sin saber qué decir.

Sin embargo, lo peor es el silencio social. Cuando en público, por alguna razón vivo los tiempos de espera de los efectos de los medicamentos y nadie pregunta. No es normal caminar con pasos cortos y tropezar, no es normal hablar sin coordinar la voz y que salgan palabras como conteniendo la respiración, no es normal no poder tomar una cuchara. No es normal, sin quedarme en el análisis sobre la normalidad, para una persona joven todavía. Y si el silencio no es bueno, los juicios a priori son más dañinos todavía. Como en el supermercado, comprando tarros de conservas y acostumbrada a leer las etiquetas, me muevo con lentitud, pareciera que mis movimientos son estudiados y los vigilantes no me quitan la vista de encima, con la incomodidad, estoy nerviosa, y mis movimientos son más torpes todavía. Nadie pregunta

13. Fromm plantea la necesidad del hombre de un sistema orientativo, que se transforme en su base del equilibrio emocional, y cuando éste siente amenazado el equilibrio, tiene dos caminos, el de la agresión y el de la fuga. (Op. cit., p. 203)

Feminismo/s 13, junio 2009, pp. 21-32 
si tengo algún problema, es más sencillo asumir que quiero llevar algo a mi bolso.

\section{La díscola-capacidad}

La discapacidad está principalmente relacionada con la sociedad en la que estamos insertos. La OMS hace una distinción entre deficiencia, discapacidad y minusvalía. Específicamente, en cuanto a discapacidad, señala:

Cualquier restricción o ausencia de la capacidad funcional para realizar actividades cotidianas en la forma o dentro del margen que se considera normal a un ser humano. Las discapacidades son siempre consecuencia de alguna deficiencia, pero éstas a veces no producen discapacidad, por lo que podríamos decir que hay más deficiencias que discapacidades. Las discapacidades representan trastornos funcionales a nivel de la persona. ${ }^{14}$

Mientras tanto, el yo interno se moviliza sin parar, sin importarle el peso de la mirada de la sociedad, que no está preparada para enfrentarse a una persona lenta y desequilibrada en su andar, ni siquiera parece preparada la sociedad para los colores e idiomas diferentes. Esa falta de tolerancia heredada del colonialismo, que nos obliga a ver al distinto del Mismo como Otro, un Mismo tan distinto como intolerante y un Otro separado del axioma «hecho a imagen y semejanza», una imagen de barbarie, y para ponerse a salvo de ese otro diferente, Mismo le impone una máscara ${ }^{15}$ para ocultar lo que no quiere ver, la diferencia que es incapaz de comprender y por lo tanto de aceptar.

El Otro constituye una imperfección en la belleza plástica de la llamada normalidad e imposibilitado de entender el lenguaje del Otro, le impone sus códigos. Incapaz de comprender sus diferentes capacidades, acusa el desorden, la indisciplina del Otro, pues «la disciplina fabrica así cuerpos sometidos», el cuerpo que acusa una enfermedad no puede ser sometido, la disciplina «disminuye las fuerzas del cuerpo (en términos de obediencia política)» lo individualiza, lo marca, para ejercer poder sobre él ${ }^{16}$. En este sentido, los enfermos son el Otro, diferentes de lo establecido dentro de lo normal, existe un problema de disciplina y se les impone el castigo de la individualización como discapacitados.

Si entendemos discapacidad simplemente como falta de capacidad, cierto, me falta capacidad para correr una maratón o los 100 metros planos. Conozco

14. Fuente: http://www.asoc-ies.org/docs/indiexso_muj_dis.pdf, consultado el 11/05/2009.

15. Foucault, M. Las Palabras y las cosas: Una arqueología de las ciencias humanas. Barcelona, Ed. Siglo XXI, 1997, p. 56.

16. FOUCAUlT, M., «Vigilar y Castigar, Nacimiento de la Prisión». Madrid, Editorial S. XXI, p. 160.

Feminismo/s 13, junio 2009, pp. 21-32 
pocas personas que podrían hacer eso en verdad, y acaso ¿les han dado los documentos de la discapacidad? Consumo a diario, cada cuatro horas un cóctel de medicamentos por prescripción del neurólogo, y gracias a eso muevo mis manos y puedo crear. ¿Acaso todos los que toman algún medicamento son discapacitados? Físicamente presento una diferencia al caminar, al moverme y subo escalas con alguna dificultad, ¿me hace eso discapacitada? Las personas que se han pasado de copas deben ser entonces discapacitados temporales ya que no coordinan los movimientos y lo que es peor, no razonan. Sin embargo, la gente les sonríe, los amigos les aplauden y el discapacitado temporal se siente muy bien, animado para continuar en su estado.

Prefiero hablar de díscola-capacidad en un encuentro entre la desobediencia o la indisciplina en la que insisto, como heredera de las indígenas rebeldes aymaras, frente al parkinson. Lo asumo como la enfermedad que es, pero me opongo fuertemente a permitir su ingreso en mi círculo íntimo. Desobedezco las normas cuando prefiero enfrentar la vida como si no existiera esta discapacidad. Díscola-Capacidad, porque ha desobedecido las normas y en ese preciso instante en que se ha rebelado al destino de una enferma de parkinson, han emergido condiciones, talentos o aptitudes diferentes que movilizan la parte no fragmentada, la parte que lucha por no deshilacharse.

«Nayaxa, warmi kankatajxa Uñt’astwaNärak chacha, närak warmiwa, Kawkhansa sayt'asta ${ }^{17}$. Yo se quién soy, pertenezco a la naturaleza, y como parte de ella, sigo los ciclos que me corresponden, soy hombre y soy mujer, como los cerros y quebradas, todo en la naturaleza es dual.

\section{El postgrado, la Universidad}

En pleno derecho del ejercicio de la necesidad de trascendencia, encontrando en los actos de creación y razonamiento el camino a la salvación de la autodestrucción, que no es otra manera de satisfacer la necesidad de trascender, postulo al magíster e ingreso a estudiar, después de muchos años de haber dejado las aulas. Diferentes estudios plantean el logro ${ }^{18}$ como una de las necesidades presentes en todos los individuos y se plantea como la necesidad de superar obstáculos o el cumplimiento de metas. En definitiva sea cualquier explicación, lo concreto es que a partir del punto de inflexión, surge una necesidad de protección, trascendiendo las funciones cognitivas, adquiero vida

17. villanueva, B. En X. AlbÓ, Raíces de América. Madrid, Alianza Editorial UNESCO, 1998, p. 360. Fragmento de poema en aymara. Esas líneas traducidas al castellano significan «Yo conozco lo que valgo como mujer, dondequiera me alzo, yo hombre, yo mujer».

18. McClelland, D. Estudio de la motivación humana. Madrid, Narcea, 1989.

Feminismo/s 13, junio 2009, pp. 21-32 
a través del conocimiento ${ }^{19}$. Y trasciendo en la medida que abordo con creatividad el desafío de vivir con el parkinson. Con un poco de temor, propio de las circunstancias de inseguridad que dan la inestabilidad física y los 45 años. ¿Acaso sé yo si mañana los medicamentos harán efecto? ¿Podré ir a clases normalmente? Existen exigencias horarias, de asistencia. ¿Será capaz mi mente de aprehender los contenidos, de generar conocimiento?

Medicamentos tomados en los horarios precisos para que alcancen su efecto hasta, al menos, el término de las clases, y otros factores cotidianamente han estado en el transcurso del primer año y avanzo bien por el segundo. Con buenas calificaciones y media beca docente, he podido financiar parte de los estudios que de otro modo no sería posible, ya que gran parte de mi pensión de invalidez cubren los gastos médicos. No ha sido fácil, en ocasiones cuando debiendo estudiar, sencillamente no puedo sostener bien un libro entre las manos. Pero no permito que impida conseguir el objetivo y busco documentos relacionados con el tema, en internet, para leerlos formato pdf.

No hay tiempo para la quietud física, no hay espacio para la rigidez, menos para la inmovilidad mental. Siempre hay movimiento, aunque éste no sea visible, estudio, investigo sobre temas de agua, indígenas, desarrollo, mujer, migraciones. Todo lo que encuentro, porque es mejor saber que algo no está bien hecho, que no saber nada. En este espacio académico aprendo y avanzo, no sé hacia dónde. Sólo sé que avanzo, a veces es suficiente con llegar al término del día y pensar en lo que aprendí, otras veces postulo al futuro y establezco compromisos para participar en algún evento académico a futuro. Aunque el parkinson es el acompañante fantasma, no estoy atada y la rigidez en ocasiones solo es un detalle, un lunar que puedo llevar dignamente. Lo mismo durante las exposiciones propias del magíster, coordinada o no, lo que aprendo y enseño dejan a un lado la incomodidad de la enfermedad, que es mayor para quienes miran que para mí que ya lo asumí.

\section{El agua}

Esta misma oportunidad de estudiar me ha permitido colaborar en la formación de la conciencia ciudadana sobre la naturaleza y la protección de los ecosistemas de las comunidades indígenas del norte de Chile. Desde el conocimiento, puedo denunciar aquellos hechos que afectan a las comunidades indígenas. La distancia y la geografía de difícil acceso, problemas como la contaminación, la extracción de minerales en ecozonas protegidas, faltas a

19. Zemelman, H. et al. Necesidad de Conciencia. Barcelona, Antrophos Editorial, 2002, p. 78. 
la legislación por parte de grandes empresas que extraen, explotan, y obtienen importantes beneficios económicos mientras que las comunidades donde generaron sus recursos siguen permaneciendo en la pobreza, la falta de oportunidades verdaderas y la discriminación. Las dificultades o inoperancias gubernamentales para supervisar el cumplimiento de las normativas es otro aspecto preocupante desde el punto de vista de la investigación.

Las diversas etapas del curso de vida que intervinieron en esta formación evolutiva donde «la vida lucha contra las restricciones de la materia, los caminos tienden a seguir hasta los límites de sus poderes» ${ }^{20}$ en condiciones duras a veces, alegres, fuertes, derribadoras y definitivas, tenían que servir ahora, y gracias a que vivo en un tiempo cronológico marcado por el uso de la tecnología, basta un computador, mucha lectura, para iniciar por ejemplo una campaña para que el boro (b) sea incluido en las normas de calidad del agua potable de Chile. ${ }^{21}$

La población de la ciudad de Arica, en la frontera con Perú, es abastecida con agua potable extraída de fuentes naturales que presenta altos índices de boro, no permitidos en los estándares sugeridos por la OMS (WHO) y las autoridades no regulan la presencia de boro, es decir, éste pasa libremente desde las fuentes naturales a las tomas domiciliarias de agua de consumo humano.

La campaña todavía continua, es lento el trabajo de transmitir a las autoridades las inquietudes y necesidades de pobladores que habitan a más de 2.000 $\mathrm{kms}$. de la ciudad capital. Escribo siempre sobre el tema, buscando nuevos resultados del mundo científico que reflejen las consecuencias del consumo prolongado de boro a través del agua potable. En ocasiones, los artículos avanzan a dos palabras por minuto porque ya pasó el efecto de los medicamentos.

\section{Balance}

Lo mejor de este tiempo es lo que decidí hacer con el punto de inflexión, con este giro en transcurso de mi vida. No iba a ser negativa, mi tiempo de llanto por los rincones fue tan solitario como necesario. Solté las desventuras al

20. FEYTO, L. Encuentros y tensiones entre ideologías. Madrid, Universidad Pontificia de Comillas, 2006, p.75.

21. La NCh 409/2005 establece parámetros de calidad para el agua potable. Según la OMS, uno de los elementos químicos limitados en cuanto a su presencia en el agua potable es el boro, para el cual sugiere $0,5 \mathrm{mg} / \mathrm{l}$. Las aguas que alimentan en Arica a la compañía distribuidora de agua potable presentan en forma natural parámetros que van desde los 14 a los $25 \mathrm{mg} / \mathrm{l}$ de boro, varias veces más que lo sugerido por la OMS. Existe la tecnología para abatir los niveles de boro, sin embargo, las autoridades hacen caso omiso, pues, según el Ministerio de Salud del país, no está comprobado que el boro sea dañino para la salud humana.

Feminismo/s 13, junio 2009, pp. 21-32 
viento y éste secó mis lágrimas. El evento inesperado era un bienvenido kairós, un símbolo de felicidad, de innovación, de oportunidad ${ }^{22}$ de movimiento. Un cuerpo detenido, tal vez, pero una psiquis en movimiento constante, que iba a seguir integrando el espacio y el tiempo presente. El instante, el quinto punto cardinal que vale más que mil promesas. Hoy, este minuto, ahora es el tiempo que vale, pues entre la realidad de la enfermedad y la capacidad de movilizar el pensamiento, sólo existe este tiempo real y concreto. Un inmenso relámpago de luz que iluminó un nuevo camino para mí, antes y después de la enfermedad, antes y después del asumir la discapacidad. Una oportunidad de tomar esta vida que me ha sido prestada para jugar como buena representante de lo femenino, múltiple, lúdica y absorbente. Juego a que soy sana, juego a que uso pilas y cuando tomo l-dopa me muevo casi normal y hago cosas que duren menos de cuatro horas, porque entre dosis y dosis soy otra vez un juguete sin pilas. Y aun así, en cuanto cuerpo sin tiempo, sin espacio, sin movimiento, sigo avanzando, deseando que las neuronas sanas se multipliquen en la nigra ${ }^{23} \mathrm{y}$ se multipliquen de este modo los efectos de los medicamentos para tener más tiempo y más espacio, aunque la centralidad permanece en el ahora.

La enfermedad de parkinson es crónica. No tiene remedio conocido, los tratamientos en base a medicamentos cooperan en la función dopaminérgica pero con el tiempo el deterioro se acentúa y tarde o temprano, las dosis no serán suficientes para permanecer con tiempos buenos. Además, la fragilidad de este estado permite que otras enfermedades puedan presentarse, como ya ha ocurrido con una pleuroneumonía el invierno pasado. Entonces cuido mi alimentación y no me expongo, cuido a los míos, los cuales aún me ven fuerte, los que no supieron que viví un breve espacio de tiempo entre la vida y la muerte, porque estar en medio de un punto de inflexión como éste, bien puede llevarnos directamente hacia el final.

Pero lo mejor de todo es que pese a arrastrar una enfermedad discapacitante, tengo la certeza de estar capacitada para hacer muchas y mejores cosas que antes. El inmenso regalo que entrega alguien cuando sonríe, cuando le tiendes la mano, es lo mejor de cada día. Espero solamente un día bueno, donde los medicamentos hagan efecto y deseo ese día, sólo ese día, alegrarme de haberlo vivido.

22. VAlencia, G. Op. cit., p. 62.

23. Llamada sustancia nigra o negra, es un núcleo nervioso ubicado en el mesencéfalo, que se distingue por la pigmentación oscura que da origen a su nombre. Allí se degeneran las células dopaminérgicas. Cuadernos de Neurología, Pontificia Universidad Católica de Chile, Vol. XXII (1997) - Consulta web 08/05/2009 <http://escuela.med.puc.cl/paginas/publicaciones/Neurologia/cuadernos/1997/pub_09_97.html>. 